\title{
Da ação folhetinesca à cena intimista: um conto romântico de Casimiro de Abreu
}

\section{Maria Cecília Boechat}

Resumo: Análise do conto "Camila - Memórias duma viagem", de Casimiro de Abreu, visando a demonstrar que um procedimento fundamental do texto - a condução das ações da narrativa para o âmbito íntimo da personagem - estabelece um distanciamento crítico em relação aos modelos folhetinescos, com os quais a prosa romântica brasileira tem sido recorrentemente confundida. Palavras-chave: conto brasileiro, folhetim, prosa romântica.

Abstract: This paper aims at analysing the short story named "Camila - Memórias duma viagem" (Camille - Trip Memories), by Casimiro de Abreu, in order to demonstrate that its basic narrative procedure - a textual strategie focused on the character's inner self-establishes a critical difference between Abreu's approach to literature and the standard newspaper serial, which the Brazilian prose from the Romanticism has usually been compared to. Keywords: Brazilian short story, newspaper serial, romantic prose. 
Do ainda hoje afamado poeta Casimiro de Abreu, não causaria espécie dizer ser mau poeta: é avaliação unânime entre historiadores e críticos do romantismo brasileiro. Nisso, porém, não se distinguiria de muitos de seus pares, cujas obras se mantêm no cânone literário brasileiro mais por motivos históricos do que propriamente estético-literários. ${ }^{1}$ Afinal, de modo geral (e generalizante), todo o nosso romantismo é tido, por princípio, como formalmente malcuidado, porque tributário das influências francesas, supostamente resultantes, por sua vez, de uma concepção já deturpada das fontes alemãs. Assim, como poeta, Casimiro de Abreu seria um representante, dentre outros, de um romantismo tardio, tendente antes ao excesso emotivo que à reflexão crítica, "ingênuo", e não "sentimental”, nos termos definidos por Schiller. ${ }^{2}$

Como prosador, o escritor teria destino ainda mais rigoroso, sendo hoje praticamente desconhecido. Provavelmente, somente estudiosos interessados na história da prosa ficcional brasileira têm conhecimento de sua produção nesse campo. A explicação, por um lado, pode estar na própria exiguidade da produção: nas Obras de Casimiro de Abreu, organizadas por Sousa da Silveira (1955), ${ }^{3}$ temos acesso a três narrativas - "A virgem loura (Páginas do Coração)", "Camila - Memórias duma viagem” e "Carolina” -, das quais apenas uma, "Camila", foi selecionada para a antologia do conto romântico brasileiro organizada por Edgard Cavalheiro e editada por Mário da Silva Brito (1960). ${ }^{4}$ Por outro lado, trata-se, de fato, de um conjunto, além de pequeno, irregular, ou, para tudo dizer, dificilmente qualificável segundo o gosto literário contemporâneo. De todo modo, por uma razão ou outra, ou, ainda, pelo próprio desprestígio que o conto romântico conquistou junto à historiografia e à crítica literária brasileiras, a fortuna crítica desse conjunto também é parca. Sousa da Silveira, sem desmentir a fama do poeta, considera sua prosa "natural, fluente e leve", correspondente ao estilo do poeta, "suave, espontâneo, simples, conciso, claro". Às qualidades gerais da prosa

Este ensaio é resultado parcial de pesquisa de pós-doutorado realizada junto à UNESP em 2009.

Schiller distingue a arte "ingênua", ou emotiva e espontânea, da arte "sentimental", já propriamente romântica e moderna, marcada pela "atividade reflexionante". Cf. SCHILLER. Poesia ingênua e sentimental. São Paulo: lluminuras, 1991.

3 SOUSA DA SILVEIRA (Org.). Obras de Casimiro de Abreu. Rio de Janeiro: Ministério da Educação e Cultura, 1955. Essa é a edição que se tomou como referência para as citações posteriores, que serão indicadas no corpo do texto com o número da página entre parênteses.

4 CAVALHEIRO, Edgard (Sel.). O conto romântico. Introd. e notas Mário da Silva Brito. Rio de Janeiro: Civilização Brasileira, 1961. (Panorama do conto brasileiro 2). Ressalte-se o acerto da seleção de Edgard Cavalheiro, que soube içar, do pequeno conjunto, justamente a exceção, tanto no que diz respeito às qualidades intrínsecas ao texto, quanto a sua adequação ao gênero narrativo a que se dedica a coletânea.

272 • BOECHAT, Maria Cecília. Da ação folhetinesca à cena intimista 
de Casimiro de Abreu, Sousa da Silveira acresce, a respeito de "Camila", certa "facécia", 5 efeito causado por um procedimento narrativo claramente indicado pelo crítico:

Começando a desenrolar-se o entrecho, momento em que a curiosidade se nos aguça, interessada da continuação da narrativa, cessa o escrito, que ficou inacabado; e a sensação de pena [,] que então nos invade, é documento cabal das qualidades de imaginação de Casimiro na criação de cenas e situações, e da sua habilidade no expô-las e encadeá-las, prendendo a atenção do leitor. Fica-se com a convicção de que, com o poeta, perdemos igualmente um excelente prosador. ${ }^{6}$

Apesar do comentário, no todo, desfavorável, encontramos aqui não poucas sugestões valiosas para nossa releitura desse conto. Porque, de fato, uma das qualidades da narrativa está no modo "natural, "fluente", com que se mostra já distanciada dos excessos que marcam a primeira prosa curta ficcional brasileira (e sempre tributados ao pretenso excesso sentimentalista de nossos prosadores românticos): excessos de adjetivação e de expansões derramadas que compõem o tom melodramático dessa produção inicial e que tanto desagradam aos leitores atuais. E que, ademais, explicariam a "pobreza" de nossas primeiras manifestações na forma concisa do conto. ${ }^{7}$ A essa "naturalidade" cai bem, sem dúvida, o laivo jocoso, de "facécia", como o definiu Sousa da Silveira, e esta é outra sugestão importante: há de se estar a certa distância dos modelos melodramáticos folhetinescos que grassavam nos jornais oitocentistas, desde a década de 1830 também no Brasil, para se poder fazer graça, ou seja, para se tomar certo distanciamento crítico em relação a esses modelos - com os quais a prosa romântica de "Camila" não deveria ser confundida.

A parte mais espinhosa da crítica de Sousa da Silveira tem, ainda, a qualidade, como já ressaltado, de indicar com muita clareza o motivo do desagrado, e motivo propria-

"Meio-termo entre a graça e a zombaria", define o Dicionário Aurélio.

6 SOUSA DA SILVEIRA. Casimiro de Abreu: escorço biográfico. In: ABREU (Org.). Obras de Casimiro de Abreu, cit., p. XXXIII. As citações do parágrafo anterior foram retiradas da mesma página.

7 Algumas expressões utilizadas nesse trecho foram tomadas a Mário da Silva Brito, que assim discorre sobre os "vícios" da escola romântica brasileira, a seu ver, em tudo problemáticas para a forma do conto: "São exatamente esses vícios que impedem o florescimento de uma forma narrativa que repudia a prolixidade, a eloquência, o excesso de imaginação, a fantasia, o sentimentalismo, as expansões derramadas, a exuberância de emoções e de linguagem. Tristão de Ataíde vê, nessa situação, o modo de explicar a 'extrema pobreza do conto romântico'. É essa também a opinião de Edgard Cavalheiro". BRITO. Nota introdutória. In: CAVALHEIRO, Edgard (Sel.). O conto romântico, cit., p. 2-3.

Teresa revista de Literatura Brasileira [12|13]; São Paulo, p. 271-286, 2013 • 273 
mente literário: a seu ver, a finalização da narrativa seria falha por deixar a narrativa em suspenso, aparentemente sem solução. Entretanto, é conveniente atentar, antes, para a perfeita unidade da estrutura narrativa, que faz duvidar da hipótese de que o autor tenha simplesmente abandonado a escrita ou a publicação do restante do texto, deixando-o inacabado. A retomada dos movimentos mais amplos do conto e de algumas de suas passagens tentará esclarecer o que aí vai dito.

Dividida em três "capítulos", a narrativa é precedida por um prólogo do autor-narrador que se constitui de reflexões irônicas sobre o gênero romanesco: ${ }^{8}$

Decididamente estamos na época dos romances. Está provado que não se pode passar sem eles; todos são necessários, porque todos são úteis. Uns deleitam pela suavidade do estilo; outros são excelentes narcóticos.

Este pertence aos últimos, e se eu não estivesse convencido de quanta utilidade pode ter ele a um desgraçado que não durma há três dias, de certo não o escreveria.

É verdade que eu incomodo horrivelmente os pacíficos cidadãos acostumados às belezas de Musset ou de Vigny, de Balzac ou Dumas, mas tenham paciência: é preciso provar de tudo. Unicamente para não se assustarem dir-lhes-ei que são apenas cinco ou seis capítulos.

Dado esse cavaco, que fica servindo de prólogo, eu principio. (p. 415)

Esse prólogo já foi devidamente comentado por Karin Volobuef como um exemplo, na literatura brasileira, da presença e atuação do espírito da ironia romântica, no sentido dos pensadores alemães. Como argumenta:

A passagem [...] é destituída de qualquer intenção no sentido de provar a veracidade da história ou de envolver emocionalmente o leitor. Em tom irônico, talvez até um pouco cínico, o narrador ridiculariza sua produção ao equipará-la a um bom sonífero [...]. O efeito de estranheza aí provocado é tanto mais acentuado na medida em que tal afirma-

8 A indistinção entre as formas narrativas ficcionais - conto, novela e romance - marca quase todo o século XIX, situação que parece mudar apenas em torno dos anos 1880. Por essa razão, continuaremos usando o termo capítulo para nos referir a suas partes, muito embora a narrativa se configure, nos termos atuais, como um conto. 
ção se segue a palavras de louvor ao romance, em especial à frase "Uns deleitam pela suavidade de estilo", que expressa exatamente o oposto do que se pratica em seguida.

Além de não ser complacente com sua criação, o autor não resiste à tentação de zombar de seus leitores [...]. Por fim, não se poderia deixar de detectar aqui ainda um escárnio para com os grandes mestres da literatura francesa da época - cujos nomes usualmente deviam ser acompanhados por exclamações reverentes? Nosso Casimiro de Abreu desafia críticos e leitores, ídolos e idólatras; sua audácia, no entanto, perde o fôlego ao chegar ao conto em si, mais uma história de rapaz rendido aos seus amores. ${ }^{9}$

Para dar um passo além do que é avançado por Volobuef e estender sua análise do prólogo à narrativa como um todo, cabe ressaltar que "Camila" apresenta certas peculiaridades (talvez) inovadoras no vasto campo de publicação desse tipo de história em seu tempo. Se considerarmos a tradição das narrativas ficcionais intensamente publicadas em jornais e revistas do século xIX desde a década de 1830, há de se reconhecer que o conto de Casimiro de Abreu se destaca justamente pelo comedimento no tratamento da trama amorosa - comedimento, repetimos, adequado ao estilo "natural e fluente" detectado por Sousa da Silveira, e ressaltado, com razão, também por Volobuef. Estamos longe, aqui, dos grandes dramas, do "transbordamento de lamúrias, lágrimas, alegrias, arrependimentos, perdões” que caracterizam, como observa Antonio Candido, uma das tendências iniciais da literatura brasileira, por ele denominada "sentimental".

Chama a atenção, de fato, como, diferentemente do que ocorre nessa vertente, pouca coisa acontece na história. Note-se como o que seria o motivo de conflito no enredo é desfeito tão logo a situação é armada. Quando nosso personagem, Casimiro, ${ }^{11}$

9 VOLOBUEF, Karin. Frestas e arestas. A prosa de ficção do romantismo na Alemanha e no Brasil. São Paulo: Fundação Editora da UNESP, 1999, p. 271-2. Cabe ressaltar, na mesma linha de leitura do prólogo proposta por Volobuef, a ironia no modo como são prometidos mais capítulos do que os que de fato são apresentados: "Unicamente para não se assustarem", afirma o narrador, "dir-lhes-ei que são apenas cinco ou seis capítulos". (Grifo nosso.)

10 CANDIDO, Antonio. Formação da literatura brasileira, vol. 2. Belo Horizonte: Itatiaia, 1981, p. 124. Cabe atentar para a diferença no uso do termo "sentimental", em oposição ao estabelecido por Schiller. Ver nota 2 deste ensaio.

11 Certamente motivado pela coincidência do nome da personagem com o do autor, Mário da Silva Brito afirma, a respeito de "Camila", tratar-se de "história de sabor autobiográfico". BRITO, Mário da Silva. Casimiro José Marques de Abreu. In: CAVALHEIRO, Edgard (Sel.). O conto romântico, cit., p. 45. Biógrafo do escritor, Sousa da Silveira, todavia, abstém-se de qualquer comentário nesse sentido. 
convidado a ser padrinho de casamento de seu amigo Ernesto, e desconfiando tratar-se da mesma moça por quem se encontrava apaixonado, procura inteirar-se da situação, perguntando-lhe, em tom trivial, se a ama, a resposta de Ernesto é fria e calculista:

- Ora, filho, tornou-me Ernesto, deves saber que é palavra que não há no meu dicionário. Ela casa-se comigo por capricho, por fantasia; e eu cedo a essa fantasia, a esse capricho, porque ambiciono ser rico, porque casando-me venho a ser possuidor da fortuna colossal de Camila. (p. 424-5)

Nenhum problema, portanto, quando, em outro diálogo, após se certificar de tratar-se da mesma moça, a personagem revela ao amigo a difícil situação em que se encontram. O transbordamento sentimentalista é evidente no modo que a personagem descreve os motivos de sua paixão, mas a ponta melodramática (e, principalmente, a ponta do conflito dramático) é de antemão desativada pela reação amistosa do noivo:

- Ora, Ernesto, se tu amasses uma mulher de certo não irias assistir ao seu casamento com outro.

Ernesto levantou-se e travou-me da mão.

- Amas Camila?! Perguntou-me ele.

- Amo-a sim.

- E ela?

- Não sei; ou para melhor dizer: nem me conhece, porque lhe falei unicamente uma vez.

- Oh! Oh! Fez Ernesto estalando um fósforo e mordendo com todo o vagar o charuto de um pataco, temos paixão romântica? Estou com vontade de saber essa história.

- Pois eu ta conto. É simples como o são todas as histórias de amor. Camila esteve em Lisboa, vi-a como todo o mundo a viu; mas o que ninguém fez, fiz eu: amei. Cruzei um segundo os meus olhos com os dela, e aquele olhar terno e lânguido fez-me mal. Desde a primeira vez que a vi pensei só nela, segui-a por toda a parte porque tinha necessidade de a ver, era um ímã que me atraía.

Escuta, Ernesto, era uma paixão louca, uma efervescência dos sentidos, um desvario da razão. Teria dado metade da minha vida por um beijo daquela mulher; teria até dado a minha alma para rolar-me como um sibarita no divã em que ela tivesse estado reclinada, para respirar os perfumes inebriantes que a cercavam. (p. 426) 
O diálogo continua, com a personagem contando sobre esse único, mas definitivo encontro. Ao final do que constitui já um monólogo, a fala da personagem e sua exaltação são interrompidas pela chegada de uma carruagem, em cena que finaliza o terceiro capítulo (e a narrativa):

Mal tinha acabado essas palavras, quando uma carruagem parou à porta do Hotel.

- Vem a propósito, disse Ernesto depois de ter chegado à janela.

- O quê? A carruagem?

- Sim, é o trem de Camila que vem buscar-me.

- Deixas-me já?

- Pelo contrário, levo-te comigo.

- Estás doido!...

- O quê! Pois recusa-me a acompanhar-te?

- A casa dela, recuso-me.

- Mas é que não vamos agora lá.

- Então acompanho-te.

Descemos a escada, e dois minutos depois rodava a carruagem ao largo trote de dois magníficos cavalos. (p. 428)

O contraponto entre uma personagem cética e outra idealista e idealizada é recorrente na tradição romântica, funcionando muitas vezes como o contraste entre o claro e o escuro, dele saindo enaltecido o amor idealizado, em vista da baixeza dos amores práticos, de interesses, ou de apelos sensuais. Como, entretanto, não há continuidade do entrecho - nada sabemos sobre o rumo da carruagem e dos amores, uma vez que a narrativa termina aqui -, não deixa de ser engraçado ver o "drama" de Casimiro pelos olhos de Ernesto, o noivo que - se não traído, ao menos ameaçado em seus interesses - neutraliza a tensão, não chegando a se exaltar, sequer a interessar-se pela confidência do amigo, mas, ao contrário, mostrando-se entediado com seus arroubos. Ademais, o término da cena - e da narrativa -, com a chegada da carruagem, vem mesmo a propósito: evita, claramente, que a narrativa incorra nos excessos do modelo sentimentalista então em voga, funcionando como contenção do sentimentalismo da personagem e desvio de rota.

Cabe ainda atentar para o outro tema subvertido pela narrativa, tema tradicional de aventuras e perigos, de grandes naufrágios como também de imensidões e arroubos sentimentais - o tema da viagem (no caso, marítima) anunciado desde o subtítulo. Comparecendo no subtítulo, fica indicada a relativa importância do tema, que se 
encontra subordinado ao entrecho amoroso. Entretanto, o entrecho amoroso só existe porque, no primeiro capítulo, durante uma noite chuvosa, Casimiro relembra seu antigo sonho de conhecer a cidade do Porto, o que explica que esteja embarcando, no capítulo 2, no vapor que leva à cidade. No desembarque é que acontece a coincidência do encontro com o amigo Ernesto, e é em torno desse encontro fortuito que se desenvolve a trama de um "quase" triângulo amoroso.

Fundamental para criar as condições do encontro das personagens, a viagem, em si, é pouco significativa, porque, nela, novamente, e em coerência com o aspecto pouco dinâmico da narrativa como um todo, quase nada acontece, a não ser um diálogo superficial e indesejável (uma "maçada", arremata o narrador) com um dos raros passageiros que não se recolheram a seus beliches, vitimados que foram todos pelos males marítimos, assim descritos, não sem ironia, pelo narrador-personagem:

Gosto muito de estar embarcado: satisfaz-me o contemplar o oceano em toda a sua vastidão e isolamento; acho poesia imensa no céu profundo duma noite de maio, quando as estrelas espalham seus reflexos trêmulos sobre as águas agitadas: é-me grato ao ouvido o canto monótono dos marujos repassado de saudade... mas todas as vezes que me embarco - enjoo.

Ora, não sei se sabem, o enjoo é a moléstia mais estúpida do mundo; torna o homem num estado quase bruto, enfraquece ao mesmo tempo o corpo e o espírito. (p. 419-2o.)

Logo ele também estará recolhido a seu beliche, rendido ao enfraquecimento do corpo (sem nada fazer) e do espírito (sem nada pensar), para só se levantar para o desembarque. O segundo capítulo, enfraquecido pela ausência das duas forças romanescas - a das ações e conflitos, por um lado, e a da introspecção, por outro - só pode, então, ser breve; contará das impressões da personagem ante a vista da cidade que se aproxima e sobre o desembarque, o encontro inesperado com o amigo, a instalação no Águia de Oiro, onde, também “por coincidência”, Ernesto está hospedado.

Desse modo, como anunciado no prólogo, a narrativa frustra as expectativas, seja de fortes emoções sentimentais, seja de grandes aventuras, agindo, em suma, como bom sonífero. Em dose única, a narrativa rompe com duas fórmulas vigentes a seu tempo. Por um lado, a chegada da carruagem anula a tendência melodramática da personagem; por outro, no momento mesmo em que a narrativa poderia desenvolver-se em uma sucessão de aventuras, retomando a fórmula folhetinesca do acúmulo de peripécias, ela é interrompida. Nessa perspectiva, o conto de Casimiro de Abreu 
pouco nos oferece das complicações e peripécias desse tipo de narrativa, em que tudo - espaço, tempo, personagens - se dobra aos acontecimentos em sua vertiginosa sucessão e arbitrariedade.

O comentário de Antonio Candido a "Amância”, de Gonçalves de Magalhães (conto publicado uma década antes, em 1844), por ele considerado a caricatura da vertente sentimental, pode ser esclarecedor a respeito dos traços definidores do gênero que podemos denominar folhetinesco:

Em suma, os personagens inexistem separados do acontecimento, que os dirige de fora, imposto pelo ficcionista com uma inabilidade que mata a verossimilhança. Sobra apenas o transbordamento de lamúrias, lágrimas, alegrias, arrependimentos, perdões, convergindo para soluções perfeitamente adequadas à moral reinante. Sob esse aspecto, Amância traz uma fórmula muito usada [...]: o amor é uma série de complicações que põe os amantes à prova, a fim de melhor recompensá-los, ilustrando sempre o triunfo da virtude. ${ }^{12}$

Nesse tipo de texto, portanto, a pouca complexidade das personagens, em seus excessos sentimentalistas, melodramáticos, pouco verossímeis segundo a psicologia moderna, está articulada com o excesso de peripécias que move a narrativa. As complicações, sentimentais ou não, mostram o domínio da ação sobre a personagem, procedimento que define o gênero folhetinesco e que, por sua vez, impõe o sentimentalismo exaltado e o apsicologismo das personagens.

Se, então, o conto "Camila" pode ser lido como uma história de um rapaz apaixonado, como realmente pode e deve ser lido, trata-se sem dúvida de uma história peculiar, se confrontada com os modelos atualizados por nossa primeira prosa de ficção, período que, segundo nossa tradição crítica e historiográfica, se estenderia, com uma ou outra exceção, até o advento da prosa madura de Machado de Assis (com Memórias póstumas de Brás Cubas). Peculiar, de fato, tanto no que apresenta de comedimento no trato das expansões emotivas da personagem, quanto na retenção da potencialidade de ação do enredo, e não menos no inusitado do triunfo da virtude, não do amor e da boa moral literária, mas dos soníferos e da categoria mais geral dos narcóticos.

Daí, ser prudente atentar para o que anuncia o prólogo e, principalmente, para o primeiro capítulo, de configuração quase estática. Trata-se, nesse sentido, de um 
capítulo aparentemente - e só aparentemente - pouco relevante para a compreensão das linhas gerais do enredo. Enfim, se já surpreende a inatividade da personagem principal nos capítulos 2 e 3 , em que se desenvolve o enredo da narrativa, no primeiro $^{13}$ ela é ainda mais radical. O que temos nele é a apresentação de um rapaz recolhido ao quarto em uma noite "tempestuosa, fria, aborrecida", e que, por volta das onze horas, interrompe seus estudos, encosta a cabeça a uma das mãos e pensa. A cismar, sozinho, entediado e melancólico, ele pensa em tudo o que ama e que está longe de seu quarto em Lisboa: no Brasil, na mãe, na infância. Os movimentos dessa parte são lentos, lânguidos, em tudo opostos à tempestade que agita o ambiente externo, como a pedir mistérios e perigosas aventuras.

Saindo da primeira posição, em movimento que podemos imaginar curto e nada brusco, nossa personagem abre "maquinalmente", como que sob o efeito da saudade, a pasta onde guarda seus manuscritos - aqui uma copla apaixonada, ali as primeiras cenas de uma comédia, mais adiante o esboço de um romance, em suma, as "primeiras criações defeituosas" de um jovem de "imaginação ardente". A monotonia dessas "sorumbáticas reflexões" só é rompida na terceira página (na edição das Obras) por um acontecimento: "De repente entre os meus papéis deparei com um número já antigo do Brás Tisana". ${ }^{14}$ Acontecimento pouco significativo, parece, não sendo exatamente inesperado, ou surpreendente, encontrar-se, em meio aos manuscritos de um poeta e prosador, na pasta que ele diz ser "um bazar em miniatura, uma verdadeira Torre de Babel de confusão", o número antigo de uma revista. Claramente, o caráter inusitado da situação, que explica o uso da expressão adverbial "de repente", não reside no encontro em si da revista, mas no tipo de histórias nela publicadas, estas sim capazes de devolver certa vivacidade ao rapaz. "Sorri-me, como qualquer um teria feito", anota o narrador: "Era a jovialidade que vinha me visitar, era o estilo estouvado, cheio de espírito e malícia do chistoso companheiro da Gertrudes que vinha arrancar-me das sorumbáticas reflexões em que eu estava atolado".

Como se percebe, o estado de espírito da personagem sofre alguma modificação, e ela se completa nos parágrafos seguintes. Após voltar a folhear a pasta, novamente exclama o narrador-personagem: "Cousa estranha! Dou com outro número do Brás Tisana!”. Desta vez, trata-se do começo de "um lindo capítulo do romance de Arnal-

O primeiro capítulo se desenrola entre as páginas 415 e 419, nas quais se encontram os trechos citados a seguir.

14 Segundo informações de Sousa da Silveira, Brás Tisana é uma revista que se publicou no Porto, de 1851 a 1863. In: Obras de Casimiro de Abreu, cit., p. 428. 
do Gama - O gênio do mal'. Bem mais animado, um tanto esquecido de saudades e melancolias, confessa:

Li o folhetim com avidez e daria tudo para ler a continuação. Desde que esse romance se começou a publicar no Brás Tisana, segui-o sempre com o vivo interesse que sabe despertar o seu talentoso autor, e ora pensando no corpo airoso e flexível de Maria a namorada de Filipe, ora sonhando com essa Matilde endiabrada, ardente e caprichosa, comecei a sentir uma vontade extraordinária de ver a cidade do Porto, onde se desenrolam as cenas desse drama imenso.

Nesse ponto, a narrativa sofre uma inflexão, desenvolvendo uma oposição interna: a ambientação, a ação, a posição da personagem, que se debruça sobre si mesma, seus pensamentos sorumbáticos, tudo promove o movimento de introversão, com que o narrador desenha uma cena intimista, mas muda a disposição da personagem que, primeiro entediada, depois melancólica, percebe-se, enfim, numa disposição inversa, animada pela imaginação e pela fantasia, predisposta, em outros termos, à extroversão: "Ora, já veem que a leitura do folhetim tinha mudado completamente o curso de minhas ideias", não deixa dúvidas o narrador, que completa: "Comecei a fantasiar o Porto". Trata-se da preparação para o segundo capítulo da narrativa, em que o enredo passa a justificar o subtítulo do conto - "Memórias duma viagem". Muda a disposição da personagem, mas não muda, ainda, o ritmo das ações. O restante do primeiro capítulo consiste na exposição dos devaneios causados pela leitura do romance. Primeiro, a descrição imaginária da cidade vista do Douro, depois, o passeio por suas ruas e, enfim, a instalação da personagem na Águia de Oiro. Se há ação, a ponto de o rapaz sentir o cansaço com que chegaria à hospedaria, ela está apenas na imaginação, pois que na cena "real" (no plano da ficção, sempre é bom lembrar) ele continua com a pasta nas mãos, na mesma posição e inatividade corporal em que o encontramos de início.

Logo o relógio dará as onze horas e meia, e ele se encaminhará para o leito. Não sem antes, entusiasmado com sua fantasia, pensar ainda: "E o vapor saía no dia seguinte! E se eu fosse de passagem nele, [...] Como eu diria [...]: salve, Porto! Realizou-se enfim o meu sonho porque te vejo ainda melhor do que te fantasiara!". Antes de cair em um pesado sono, é com disposição inversa ao tédio inicial que avaliará: "Como é belo estar na cama bem agasalhado numa noite de chuva! Dorme-se como um regalo!". A passagem entre os capítulos é brusca: "Era uma bela manhã. O rio estava formoso, o sol brilhava vívido, e o Duque do Porto, coroado por um penacho de fumo, pronto 
a sair, balançava-se nas águas do Tejo”. "Eu também ia para o Porto”, anuncia o narrador-personagem, na abertura do capítulo 2.

Ora, sabendo-se que o último devaneio da personagem havia sido o de tomar o navio que partia para a cidade na manhã seguinte à noite chuvosa do primeiro capítulo, é verossímil que o encontremos, aqui, nele embarcado. É verossímil até que, chegando lá, se hospede no mesmo devaneado Águia de Oiro, muito embora o narrador se veja, para que tomemos o evento como tal - como acontecido no plano da realidade ficcional -, premido a argumentar pela factualidade do episódio, afirmando: "É rara a hospedaria de romance que não se chame Águia de Oiro, Leão de Oiro, Urso Branco, Urso Vermelho, ou outra coisa semelhante; no entanto afirmo que aquela em que me instalei não é invenção minha porque lá existe com efeito no Porto a hospedaria da Águia de Oiro” (p. 419). Outra será a leitura, porém, se atentarmos para a série de coincidências entre a narrativa de "Camila" e o enredo do romance lido por nosso rapaz, que contém e enuncia elementos importantes: o romance traz, como se informa, cenas de um "drama imenso" passado justamente "na cidade do Porto", seguido por Casimiro com "vivo interesse", exatamente porque interessado em uma história de amor em triângulo, envolvendo certa "Maria a namorada de Filipe". Atente-se, ademais, que, nas reflexões sorumbáticas da personagem, incluem-se as saudades da pátria, da mãe e das ilusões de glória literária da mocidade, mas nada sugere a dor de algum amor perdido. Esta é uma sugestão evidentemente ligada ao romance lido, bem como o é a lembrança do acalentado desejo de conhecer a cidade do Porto, lembrança que o lança aos devaneios de uma viagem à cidade.

Os finais dos capítulos 1 e 3 são ainda muito significativos quando confrontados em detalhe. Naquele, sonolenta, já deitada, a personagem ainda tem tempo, antes de adormecer, para observar: "A chuva continuava a cair, alguns relâmpagos de vez em quando alumiavam o espaço, e um silêncio imenso só quebrado pela queda da água, envolvia o meu quarto". As últimas sensações da personagem são, portanto, sonoras, e elas consistem no motivo de seu derradeiro pensamento, com o qual se fecha o capítulo:

Foi por isso que não conversei muito tempo com o travesseiro. Dous minutos depois, se não estava morto, também não dava sinais de vida. Podia chover, trovejar, tocarem música ou dançarem, para mim era o mesmo. Dormia a bom dormir! (Grifo nosso.)

Releia-se o fecho da narrativa: "Descemos a escada, e dois minutos depois rodava a carruagem ao largo trote de dois magníficos cavalos”. Encerra-se assim a terceira parte e, além da coincidência da marcação temporal, que indicara, no primeiro 
capítulo, a passagem de estado consciente para o onírico, a última referência da narrativa é também a uma sensação sonora. O fecho circular é perfeito: ainda ecoando, o som do trote dos cavalos recupera a imagem inicial, geradora de toda a narrativa e desenhada no primeiro capítulo, de um rapaz que dorme ao som tamborilante e encadeado da chuva. Então, não seria inverossímil (nos termos de coerência interna), e elementos da narrativa trabalham para isso, interpretar os capítulos que se seguem não como o relato interrompido das aventuras "vividas" pelo narrador, mas, antes, como a reelaboração, até o ponto que lhe é possível recuperar, do que ele sonhara naquela noite de tédio melancólico. Visto assim, o conto "Camila" conta outra história: a de um rapaz que, mais exatamente, dorme e sonha, rendido aos efeitos da leitura de um romance. A narrativa, dessa forma, transforma em cena o que é teoria (cheia de facécia, certamente) no prólogo, que é como que atuado, em termo livremente psicanalítico, ou figurado por meio de procedimentos literários. A situação em que a narrativa coloca o receptor do texto, por sua vez, parece confirmar a estrutura por encaixe e, tal como a personagem, ele pode pensar que também "daria tudo para ler a continuação" do folhetim, que lhe é deixada, como se pode perceber agora, intencionalmente em aberto.

Nesta perspectiva, revela-se a unidade muito bem traçada da narrativa, que responde aos preceitos da forma do conto moderno. E o que víamos como dois grandes movimentos da narrativa - um, lento, introspectivo, contido no espaço de um quarto, em contraste com outro, o da viagem e das aventuras - se recolhe a apenas um. Ao cabo, toda a história fica devidamente recolhida ao espaço do sonho e do devaneio e a apenas uma imagem estática, a de um rapaz dormindo. ${ }^{15}$

O que resta a dizer é que, nessa cena, já intimista, o que interessa ao texto não é, exatamente, o que se vê, mas o que não se pode ver quando se olha um rapaz dormindo: o mundo da imaginação e da fantasia a que tem acesso só quem está dormindo (ou sob o efeito de narcóticos ou da leitura de certos romances). Esfera romântica, afinal, e propriamente romântica. entre gêneros), pois realiza, como diria José Américo Miranda, "o desafio que a todo poeta é colocado pelo ato da criação: o de armar 'figuras no ar', como no verso de Dante ('o quanto a dir é cosa dura' em tradução de Augusto de Campos)". MIRANDA, José Américo. O gerúndio e o lusco-fusco: som e sentido em um poema de Carvalho Júnior. In: BASTOS et al. (Orgs.). Estudos de literatura brasileira. Belo Horizonte: Faculdade de Letras da UFMG, 2008, p. 90. 
Tudo transposto para uma teoria das relações entre ficção e realidade, o que se afirma aqui é a concepção de um mundo real distorcido, transfigurado pela imaginação. Se o elogio é feito aos mundos imaginários, estes não deixam de manter relação com a realidade, como sugere o fato de que a noite chuvosa, até então isolada, como composição do ambiente externo, é traduzida, interiorizada, em impressão sonora no sonho, ressurgindo transfigurada no trote largo dos cavalos. Em termos de técnica narrativa, a mesma relação é afirmada, pois, se, em "Camila", o enredo das ações aventurosas se dobra à investigação do mundo interior da personagem, num movimento em tudo contrário à função folhetinesca, essa dobra não pode prescindir dela; na verdade, depende dela para sua consecução.

Forçoso concluir, então, que, a certa altura do século XIX, que resta ainda estabelecer com mais segurança (mas certamente muito antes do que hoje tendemos a acreditar), o modelo folhetinesco - que chega a nós por tantas traduções de folhetins ${ }^{16}$ franceses, e no qual se exercitaram vários de nossos escritores oitocentistas - passou a funcionar menos como modelo do que como procedimento narrativo criticamente apropriado, feito que possibilitou a passagem, na literatura brasileira, da narrativa de ação e aventuras para as narrativas das aventuras dos mundos e movimentos subjetivos de nossa melhor prosa ficcional moderna.

Com certeza, podemos apenas saber que, à altura dos anos oitenta do século xIx, os procedimentos puramente folhetinescos - a ação composta como uma série de truques, a narrativa de composição artificiosa, mal alinhavada e arbitrária - chegavam já à completa saturação. Em ensaio datado de 1888, Araripe Júnior anunciava, com precisão, o esvaziamento do recurso, então despido de sua capacidade de surpreender o leitor, acostumado já a todo tipo de peripécias e artifícios:

As máquinas complicadas, mais na aparência do que na realidade [...] tornaram-se uma coisa tão habitual para o leitor, que, por último, dadas as primeiras linhas de um romance, nada mais fácil havia do que prever tudo o quanto devia, daí por diante, sair da pena do autor. O romancista, portanto, ficava reduzido a uma espécie de contrarregra, de cujo regimento o público comparticipava.

Usamos, até aqui, muito livremente os termos folhetim e folhetinesco, que, entretanto, merecem distinção. Por folhetim, entende-se o modo de publicação de histórias em partes, como se tornou usual na década de 1830, nos diversos periódicos oitocentistas (prática que teve continuidade até o século XX). Folhetinesco diz respeito ao gênero amplamente exercitado por autores da época, cujas características exploramos no decorrer deste texto. 
O tédio determinou a reação, e esta fez-se em direção completamente oposta. Visto ter-se o cenário do romance convertido em baldrame de teatro, afogando e multiplicando toda a importância dos personagens; visto haverem-se esses personagens transformados em marionetes ridículos, sem vida, passando a ação a ser apenas uma série de truques previstos e de facílima composição, era indispensável abandonar esse campo de visualidades, sem significação, este objetivismo de fantasia, para ocuparem-se os autores com a alma do homem e com os problemas que verdadeiramente interessavam à humanidade. ${ }^{17}$

Araripe Júnior indica, aí, a transformação por que passava a prosa oitocentista, intuindo, com acuidade, o que hoje estudiosos consideram um dos traços distintivos do romance moderno ou, para usar um termo mais amplo (capaz de abarcar também a forma do conto) da prosa ficcional moderna: a mudança do foco de interesse da composição, que se desloca, da ação, em direção à personagem. Como estabelece Antonio Candido:

Deste ponto de vista, poderíamos dizer que a revolução sofrida pelo romance no século XVIII consistiu numa passagem do enredo complicado com personagens simples, para o enredo simples (coerente, uno) com personagens complicados. O senso da complexidade da personagem, ligado ao da simplificação dos incidentes da narrativa e à unidade relativa de ação, marca o romance moderno [...]. ${ }^{18}$

O que devemos admitir, se a leitura aqui proposta for válida, é que, muito antes de essa exaustão ser constatada, o modelo já vinha sendo crítica e ironicamente minado. A data precisa desse feito é de difícil estabelecimento, como mostra o fato de "Camila" ter sido publicada no mesmo ano $\left(1856^{19}\right)$ que outra das narrativas curtas de Casimiro de Abreu, "Carolina”, de cunho nitidamente melodramático.

ARARIPE JR. Degenerescência da ficelle e queda do romantismo. In: COUTINHO, Afrânio. Obra crítica de Araripe Júnior, vol. II. Rio de Janeiro: Ministério da Educação e Cultura; Casa de Rui Barbosa, 1960, p. 38.

18 CANDIDO, Antonio. A personagem do romance. In: CANDIDO et al. A personagem de ficção. São Paulo: Perspectiva, 1976, p. 60-1.

19 As datas de publicação das narrativas curtas de Casimiro de Abreu são as seguintes: "A virgem loura (Páginas do Coração)", Correio Mercantil, 7 dez. 1857; "Camila - Memórias duma viagem", A llustração LusoBrasileira, Lisboa, 1856; "Carolina", O Progresso, Lisboa, 1856. 
E isso implica, para o estudioso da primeira prosa brasileira, suspeitar que esse distanciamento crítico deve menos ser procurado em termos de determinadas autorias ou datas das publicações do que em certos mecanismos narrativos, ainda a serem percebidos e reconhecidos como distintivos entre o exagero sentimentalista, folhetinesco, e os artifícios românticos, em que esse elemento cumpre funções outras.

Maria Cecília Bruzzi Boechat é professora de Literatura Brasileira da Faculdade de Letras da UFMG, autora de Paraísos artificiais: o romantismo de José de Alencar e sua recepção crítica (Editora da UFMG, 2003). 